\title{
Cognitive function of children and adolescent survivors of acute lymphoblastic leukemia: A meta-analysis
}

\author{
KALLIOPI MAVREA ${ }^{1}$, VASILIKI EFTHYMIOU ${ }^{2}$, KATERINA KATSIBARDI ${ }^{3}$, \\ KONSTANTINOS TSAROUHAS ${ }^{4}$, CHRISTINA KANAKA-GANTENBEIN ${ }^{1,2}$, DEMETRIOS A. SPANDIDOS ${ }^{5}$, \\ GEORGE CHROUSOS $^{2}$, ANTONIS KATTAMIS ${ }^{3}$ and FLORA BACOPOULOU ${ }^{1,2}$ \\ ${ }^{1}$ Clinic for Assessment of Adolescent Learning Difficulties, Center for Adolescent Medicine and \\ UNESCO Chair on Adolescent Health Care, First Department of Pediatrics; ${ }^{2}$ University Research Institute of \\ Maternal and Child Health and Precision Medicine, and UNESCO Chair on Adolescent Health Care; \\ ${ }^{3}$ Pediatric Hematology-Oncology Unit, First Department of Pediatrics, National and Kapodistrian University of Athens, \\ Aghia Sophia Children's Hospital, Athens 11527; ${ }^{4}$ Department of Cardiology, University Hospital of Larissa, \\ Larissa 41110; ${ }^{5}$ Laboratory of Clinical Virology, School of Medicine, University of Crete, Heraklion 71409, Greece
}

Received October 22, 2020; Accepted January 14, 2021

DOI: $10.3892 / 01.2021 .12523$

\begin{abstract}
Pediatric cancer and its treatment may have an impact on the neurocognitive functions of childhood cancer survivors (CCS). The aim of the present meta-analysis was to compare the intelligence quotient (IQ) scores between CCS of acute lymphoblastic leukemia (ALL) and controls. A comprehensive electronic search identified original research articles that reported scores of the Wechsler Intelligence Scale (WISC; WISC-III, WISC-IV and WISC-R) for children and adolescents, aged 6-16 years at evaluation, survivors of ALL and healthy controls. The included CCS had completed anticancer treatment and were in remission at the time of assessment. A total of 16 studies were included in the meta-analysis, out
\end{abstract}

Correspondence to: Professor Flora Bacopoulou, Clinic for Assessment of Adolescent Learning Difficulties, Center for Adolescent Medicine and UNESCO Chair on Adolescent Health Care, First Department of Pediatrics, National and Kapodistrian University of Athens, Aghia Sophia Children's Hospital, 1 Thivon Street, Athens 11527, Greece

E-mail: fbacopoulou@med.uoa.gr

Abbreviations: ALL, acute lymphoblastic leukemia; CCS, childhood cancer survivors; CI, confidence interval; CNS, central nervous system; IQ, intelligence quotient; PRISMA, preferred reporting items for systematic reviews and meta-analyses; SD, standard deviation; SMD, standardized mean difference; WISC, Wechsler Intelligence Scale for Children; WISC-III, Wechsler Intelligence Scale for Children-Third Edition; WISC-IV, Wechsler Intelligence Scale for Children-Fourth Edition; WISC-R, Wechsler Intelligence Scale for Children-Revised

Key words: cancer, acute lymphoblastic leukemia, survivors, learning difficulties, cognitive, IQ, intelligence, children, adolescents, chemotherapy, radiotherapy, WISC, education of 128 extracted studies, and involved a total of 1,676 children and adolescents: 991 CCS (ALL) and 685 healthy controls. Among the studies, a random effects model revealed a moderate estimate of effect size [standardized mean difference (SMD), $-0.78 ; 95 \% \mathrm{CI},-1.05$ to -0.50$]$, indicating that the WISC scores for total IQ were significantly lower in the CCS than in the controls. The mean total IQ range was 85.2-107.2 in the CCS and 88.4-114.1 in the controls. The difference in the mean total IQ between controls and CCS ranged from -13.8 to 20.6. As regards the WISC scores for verbal IQ, 11 studies were included. A random effects model revealed a moderate estimate of effect size (SMD, $-0.71 ; 95 \%$ CI, -1.05 to -0.38 ), indicating that the WISC scores for verbal IQ were significantly lower in the CCS than in the controls. Among the 9 studies that had available data for performance IQ scores, a fixed effect model revealed a moderate estimate of effect size (SMD, $-0.80 ; 95 \%$ CI, -1.09 to -0.52), indicating that the WISC scores for performance IQ were significantly lower in the CCS than in the controls. As the survival rates of children and adolescents with ALL are steadily increasing, regular, lifelong follow-up for neurocognitive late effects is imperative in order to improve their education and employment prospects and overall, their quality of life.

\section{Introduction}

Acute lymphoblastic leukemia (ALL) is the commonest pediatric cancer accounting for nearly $25 \%$ of cancers in children and adolescents under the age of 15 (1). The marked improvement in the survival rate, from approximately $10 \%$ in the 1960 s to $90 \%$ at present (2), is derived from the enhanced efficacy of multiagent chemotherapy protocols along with central nervous system (CNS) prophylaxis. Pediatric cancer and its treatment can cause medical, neurocognitive and psychological late effects throughout the lifespan of children and adolescents, childhood cancer survivors (CCS). Great emphasis has been placed on the cognitive effects of 
pediatric cancer, as previous research has demonstrated that pediatric cancer, its type and mainly its treatment, negatively affect the learning abilities of CCS and their educational achievements $(3,4)$. These findings have led researchers to suggest that, apart from clinical and psychological interventions, CCS must be examined in terms of their cognitive and learning abilities, while special education programs need to be designed for them $(3,5-7)$.

The concept of learning refers to the acquisition of new, or the modification of existing knowledge, experience, skills and behavior (8). The nature of learning is highly influenced by the social context, although the cognitive background of the individual is also important. Learning is controlled by complex cognitive and mental mechanisms, the disruption of which greatly affects learning abilities. The cognitive psychologist, Tolman, described the creation of cognitive maps in the brain, in terms of information formation and process, further emphasizing the cognitive nature of learning (9).

Approximately 5.5\% of children and adolescents aged 5-17 years suffer from chronic illnesses or disorders that withhold them from attending school classes (approximately $0.6 \%$ of the population), which renders their enrollment to special education programs mandatory (3.7\% of the population) or compels them to school absenteeism for long periods of time (1.2\% of the population) (10). The scientific interest in the educational outcomes of CCS derives from the observation that children with ALL or CNS tumors, who undergo chemotherapy or radiation therapy, demonstrate diminished cognitive functions. Emphasis is given to these types of cancer, as these two types account for approximately $40 \%$ of pediatric cancer cases worldwide (11).

Chemotherapy aggravates the cognitive-educational outcomes of children, due to white matter deficiencies resulting from disruptions in the myelination process that occurs during childhood. Detrimental effects on the brain include neuroinflammation, increased oxidative stress, reduced blood flow and the dysregulation of the DNA-repair mechanisms or the immune response. These may lead to neurocognitive underdevelopment, manifesting as reduced attention and focus ability, which negatively affect the educational outcomes of children (12).

A retrospective cohort study of 593 adult survivors of ALL and 409 control siblings, enrolled in 23 institutions in the United States and Canada, demonstrated that survivors experienced difficulties in school. Children having survived ALL had lower school grades than their siblings and attended special educational classes or classes for learning disabilities 3 to 4 times more often than their siblings without a history of cancer. Moreover, when CCS attended such classes, it took them more time to complete them, compared to their siblings. Furthermore, CCS of ALL were more likely to be absent from school for longer time periods, or even compelled to repeat an academic year. On the other hand, graduation rates from schools or colleges did not differ between CCS and their siblings. Survivors had the same probabilities as their brothers and sisters to finish high school, get into college and obtain a bachelor's degree. Nevertheless, children subject to cranial irradiation of $24 \mathrm{~Gy}$ or more and those diagnosed at a younger age (before the age of 6 years) had lower grades at school and were less likely to attend college (13).
Pediatric cancer affects intelligence in general. More specifically, CCS have been found to suffer significant impairment in attention, information processing, executive functions, memory retrieval, psychomotor and verbal skills, all of which in turn negatively affect the academic and overall learning achievements of CCS $(14,15)$.

A previous meta-analysis (16) confirmed the neurocognitive impairments in childhood ALL survivors following treatment, among which intelligence was significantly affected. This first meta-analysis explored chemotherapy- and/or radiotherapy-induced neuroimaging changes underlying cognitive function of children, adolescents and young adults whose intelligence was measured with different scales dependent on participants' ages.

The aim of the present meta-analysis was to compare the intelligence quotient (IQ) scores between children and adolescent ALL survivors, and healthy controls, and thus summarize the current evidence on the contribution of ALL on this cognitive domain during the developmentally vulnerable periods of childhood and adolescence.

\section{Materials and methods}

Search strategy. A comprehensive electronic search was held through 2 electronic databases, namely PubMed and Google Scholar until September 7, 2020. The following search terms were used: 'acute lymphoblastic leukemia AND cognitive function' 'acute lymphoblastic leukemia AND cognitive effects', 'acute lymphoblastic leukemia AND intellectual functioning', 'acute lymphoblastic leukemia AND intelligence', 'acute lymphoblastic leukemia AND IQ', 'acute lymphoblastic leukemia AND learning effects'. The references of all eligible articles were also thoroughly checked.

Inclusion and exclusion criteria. Original research studies published in the English language which reported scores of the Wechsler Intelligence Scale for Children (WISC) third edition (WISC-III), fourth edition (WISC-IV) or revised edition (WISC-R) for children and adolescents, survivors of ALL, were considered for inclusion if i) CCS were 6-16 years of age at the time of the evaluation; ii) CCS had completed their anticancer treatment; iii) CCS were in remission (complete or partial); and iv) the study included a healthy control group. Studies of patients with known pre-existing cognitive, psychiatric, neurosensory or neurodevelopmental disorders (e.g., attention deficits hyperactivity disorders) were excluded.

Data extraction. Data extracted from the selected studies included the following: Names of authors, year of publication, country, number of participants (CCS and controls), age at assessment and IQ measurement scales. The 3 dimensions of the WISC, i.e., total (full-scale) IQ, verbal IQ and performance IQ, were recorded whenever available.

Statistical analysis. Statistical analysis was performed using Review Manager software (Version 5.2, The Nordic Cochrane Centre). The association of WISC scores between the CCS and control groups was calculated using the standardized mean difference (SMD) with a 95\% confidence interval (CI). The significance of pooled SMD was determined by a Z-test. 


\section{TRISMA PRISMA 2009 Flow Diagram}

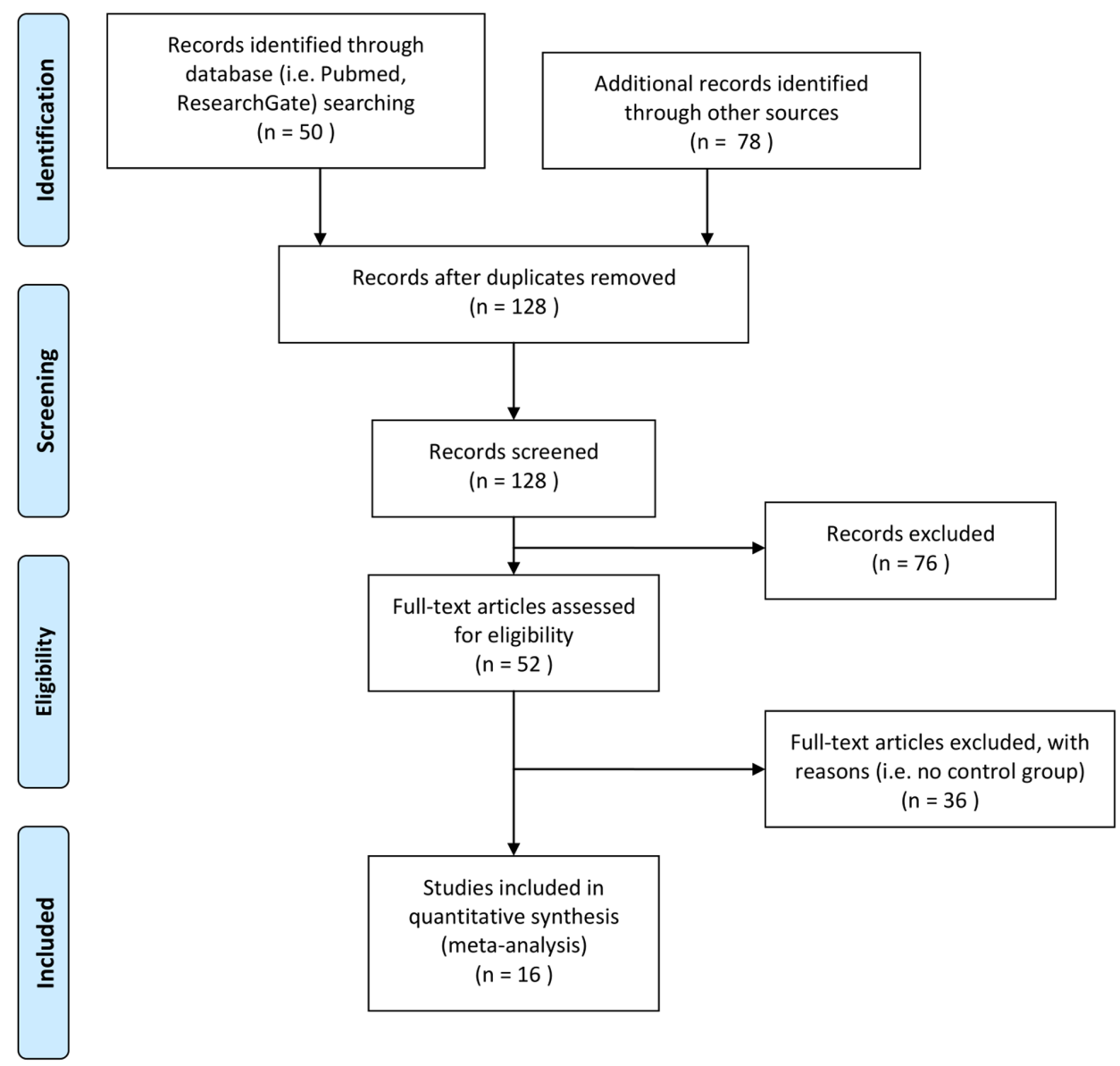

Figure 1. PRISMA flow chart of study selection. PRISMA, preferred reporting items for systematic reviews and meta-analyses.

A random effects model or fixed effects model was applied, respectively for heterogeneous or non-heterogeneous data after calculating Cochrane's Q-statistic $(\mathrm{P}<0.05$ for significant $)$ and $\mathrm{I}^{2}$ test ( $0 \%$, no heterogeneity; $100 \%$, maximal heterogeneity). A funnel plot and the Egger's test were used to estimate the publication bias. The statistical significance level was set at $5 \%(\mathrm{P}<0.05)$.

\section{Results}

Differences in WISC scores between CCS and controls. The methodology of preferred reporting items for systematic reviews and meta-analyses (PRISMA) 2009 (17) was followed. In total, 16 studies out of 128 extracted studies were included in the present meta-analysis (one was included twice; high- and low-dose) and these involved a total of 1,676 children and adolescents, 991 CCS (ALL) and 685 healthy controls. The studies by Said et al (18), Cetingül et al (19), Raymond-Speden et al (20), Anderson et al (21), Reinfjell et al (22), Lofstad et al (23), Carey et al (24), Aukema et al (25), Halsey et al (26), Zou et al (27), Kesler et al (28), Reddick et al (29), Kim et al (30), Van Der Plas et al (31), Darling et al (32) and Sherief et al (33) were included in the present meta-analysis. A total of 112 studies were excluded as they did not report the
WISC scores for each group, or they used WISC first edition, or did not include control group, or studied children mixed with adults, or included different age range subjects, or were either duplicates or reviews or meta-analyses (Fig. 1).

Table I presents a summary of the data that were extracted from the 16 studies of the meta-analysis sample. Among the studies, a random effects model revealed a moderate estimate of effect size (SMD, $-0.78,95 \%$ CI, -1.05 to -0.50) (Fig. 2), indicating that the WISC scores for total IQ were significantly lower in the CCS than in the healthy controls. Significant heterogeneity was identified across included studies $(\mathrm{P}<.001$, $\mathrm{I}^{2}=82 \%$ ). A visual examination of the funnel plots indicated no significant publication bias over all the included studies.

As regards the WISC scores for verbal IQ, 11 studies were included due to the lack of available data in the study by Carey et al (24), Zou et al (27), Kesler et al (28), Reddick et al (29), Van Der Plas et al (31) and Darling et al (32). A random effects model revealed a moderate estimate of effect size (SMD, -0.71; 95\% CI, -1.05 to -0.38) (Fig. 3), indicating that the WISC scores for verbal IQ were significantly lower in the CCS than in the healthy controls. Significant heterogeneity was identified across included studies $\left(\mathrm{P}<.001, \mathrm{I}^{2}=82 \%\right)$. The funnel plot suggested no significant publication bias over the included studies. Among the 9 studies with available data 
Table I. Summary data of the meta-analysis sample.

\begin{tabular}{|c|c|c|c|c|c|}
\hline First author, year & Participants & $\begin{array}{l}\text { Age range, } \\
\text { years }\end{array}$ & Country & $\begin{array}{l}\text { IQ measurement } \\
\text { scale }\end{array}$ & (Refs.) \\
\hline Said et al, 1989 & $\begin{array}{l}65 \text { CCS } \\
39 \text { healthy siblings }\end{array}$ & $6-16$ & Australia & WISC-R & (18) \\
\hline Cetingül et al, 1999 & $\begin{array}{l}19 \text { CCS } \\
17 \text { healthy siblings }\end{array}$ & $6-15$ & Turkey & WISC-R & (19) \\
\hline Raymond-Speden et al, 2000 & $\begin{array}{l}41 \text { CCS } \\
21 \text { children with chronic asthma } \\
21 \text { healthy controls }\end{array}$ & $6-16$ & New Zealand & WISC-R & (20) \\
\hline Anderson et al, 2000 & $\begin{array}{l}35 \text { CCS } \\
35 \text { healthy controls }\end{array}$ & $7-13$ & $\begin{array}{l}\text { Australia } \\
\text { (Melbourne) }\end{array}$ & WISC-R & (21) \\
\hline Reinfjell et al, 2007 & $\begin{array}{l}40 \text { CCS } \\
42 \text { healthy controls }\end{array}$ & $8.5-15.4$ & Norway & WISC-III & (22) \\
\hline Carey et al, 2008 & $\begin{array}{l}9 \text { CCS } \\
14 \text { controls }\end{array}$ & $7.7-25.8$ & $\begin{array}{l}\text { USA } \\
\text { (California) }\end{array}$ & $\begin{array}{l}\text { WISC-III } \\
\text { (WAIS-III for } \\
\text { ages }>17 \text { years) }\end{array}$ & (24) \\
\hline Lofstad et al, 2008 & $\begin{array}{l}35 \text { CCS } \\
35 \text { healthy controls }\end{array}$ & $8.4-15.3$ & Norway & WISC-III & (23) \\
\hline Aukema et al, 2008 & $\begin{array}{l}11 \text { CCS } \\
17 \text { controls }\end{array}$ & $8.9-16.9$ & $\begin{array}{l}\text { Netherlands } \\
\text { (Amsterdam) }\end{array}$ & WISC-III & (25) \\
\hline Halsey et al, 2011 & $\begin{array}{l}289 \text { CCS } \\
132 \text { controls }\end{array}$ & $2-16$ & $\begin{array}{l}\text { Scotland } \\
\text { (Glasgow) }\end{array}$ & $\begin{array}{l}\text { WISC-III } \\
\text { (WPPSI-R for } \\
\text { ages 2-5.9years) }\end{array}$ & (26) \\
\hline Zou et al, 2012 & $\begin{array}{l}14 \text { CCS } \\
28 \text { healthy controls }\end{array}$ & $6-17$ & USA & WISC-III & (27) \\
\hline Kesler et al, 2014 & $\begin{array}{l}15 \text { CCS } \\
14 \text { healthy controls }\end{array}$ & $8-15$ & $\begin{array}{l}\text { USA } \\
\text { (California) }\end{array}$ & WISC-IV & (28) \\
\hline Reddick et al, 2014 & $\begin{array}{l}154 \text { CCS } \\
67 \text { healthy siblings }\end{array}$ & $6-6$ & USA & WISC-III & (29) \\
\hline Kim et al, 2015 & $\begin{array}{l}42 \text { CCS } \\
42 \text { healthy controls }\end{array}$ & $5-15$ & Korea & $\begin{array}{l}\text { KEDI-WISC } \\
\text { (Korean version } \\
\text { of WISC-R) }\end{array}$ & (30) \\
\hline Van Der Plas et al, 2017 & $\begin{array}{l}130 \text { CCS } \\
119 \text { healthy controls }\end{array}$ & $8-16.9$ & $\begin{array}{l}\text { Canada } \\
\text { (Toronto) }\end{array}$ & WISC-IV & (31) \\
\hline Darling et al, 2019 & $\begin{array}{l}21 \mathrm{CCS} \\
18 \text { healthy controls }\end{array}$ & $7-16.9$ & Australia & WISC-IV & (32) \\
\hline Sherief et al, 2018 & $\begin{array}{l}100 \text { CCS } \\
50 \text { healthy controls }\end{array}$ & $5-15$ & Egypt & WISC-III & (33) \\
\hline
\end{tabular}

CCS, childhood cancer survivors; IQ, intelligence quotient; WISC-III, Wechsler Intelligence Scale for Children-Third Edition; WISC-IV, Wechsler Intelligence Scale for Children-Fourth Edition; WISC-R, Wechsler Intelligence Scale for Children-Revised; WAIS, Wechsler Adult Intelligence Scale; WPPSI, Wechsler Preschool and Primary Scale of Intelligence.

for performance IQ scores, a fixed effect model revealed a moderate estimate of effect size (SMD, -0.80 ; 95\% CI, -1.09 to -0.52 ) (Fig. 4), indicating that the WISC scores for performance IQ were significantly lower in the CCS than in the healthy controls. Significant heterogeneity was identified across included studies $\left(\mathrm{P}<.001, \mathrm{I}^{2}=75 \%\right)$. A visual examination of funnel plots indicated no significant publication bias over all included studies. The studies by Carey et al (24), Aukema et al (25), Kesler et al (28), Kim et al (30) and Darling et al (32), did not identify significant differences among different types of cancer treatment, with respect to their effects on the cognitive functioning and learning of CCS. The study by Aukema et al (25), was the only study demonstrating lower IQ levels of the control vs. the ALL group. 


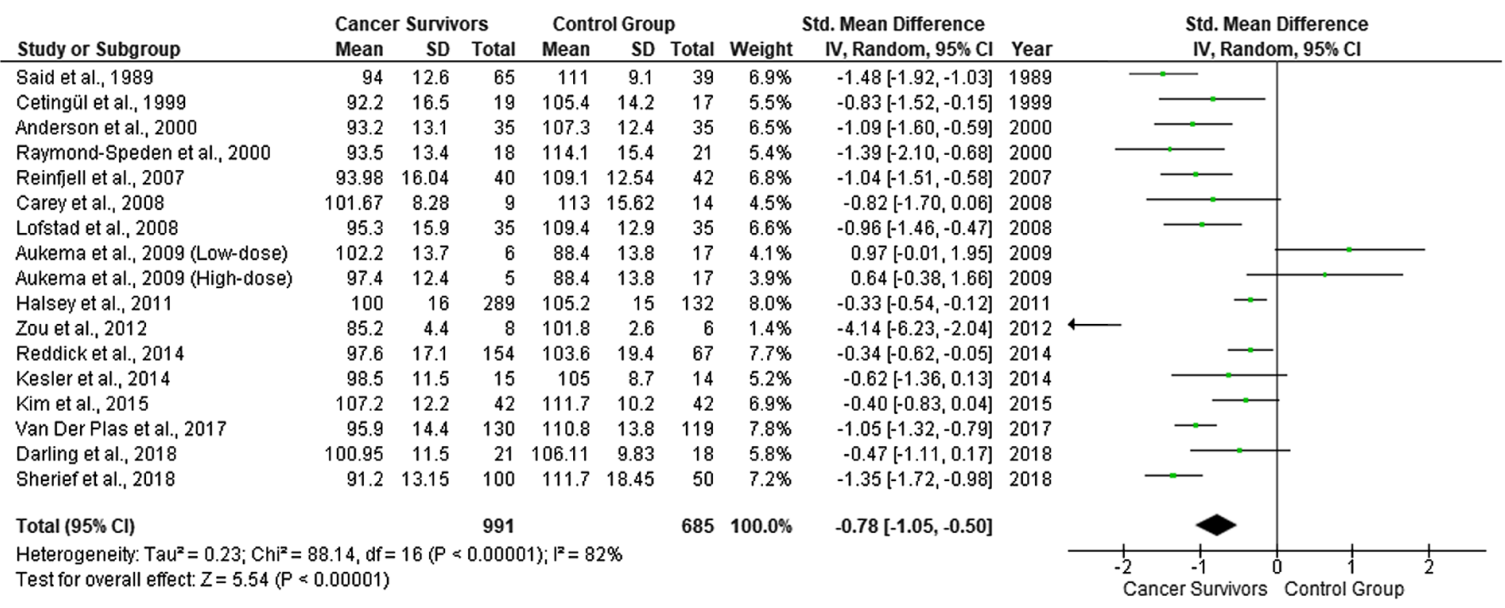

Figure 2. Forest plot presenting the meta-analysis based on SMDs for the effect of WISC total IQ. The studies listed are as follows: Said et al (18), Cetingül et al (19), Raymond-Speden et al (20), Anderson et al (21), Reinfjell et al (22), Lofstad et al (23), Carey et al (24), Aukema et al (25), Halsey et al (26), Zou et al (27), Kesler et al (28), Reddick et al (29), Kim et al (30), Van Der Plas et al (31), Darling et al (32) and Sherief et al (33). SMD, standardized mean difference; WISC, Wechsler Intelligence Scale for Children; IQ, intelligence quotient.

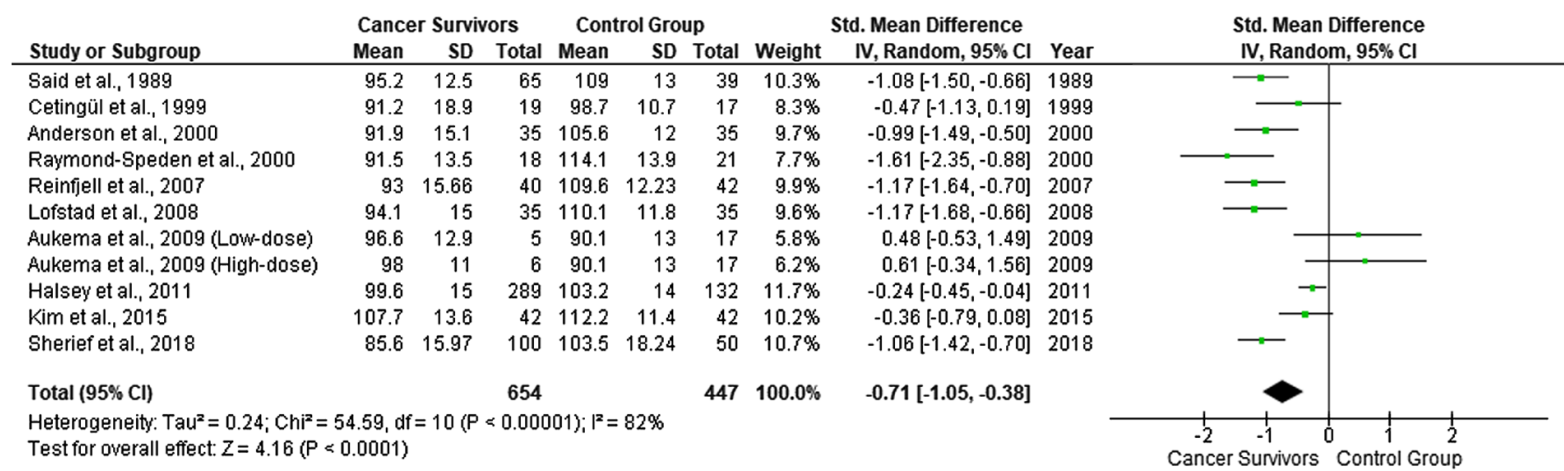

Figure 3. Forest plot presenting the meta-analysis based on SMDs for the effect of WISC verbal IQ. The studies listed are as follows: Said et al (18), Cetingül et al (19), Raymond-Speden et al (20), Anderson et al (21), Reinfjell et al (22), Lofstad et al (23), Aukema et al (25), Halsey et al (26), Kim et al (30) and Sherief et al (33). SMD, standardized mean difference; WISC, Wechsler Intelligence Scale for Children; IQ, intelligence quotient.

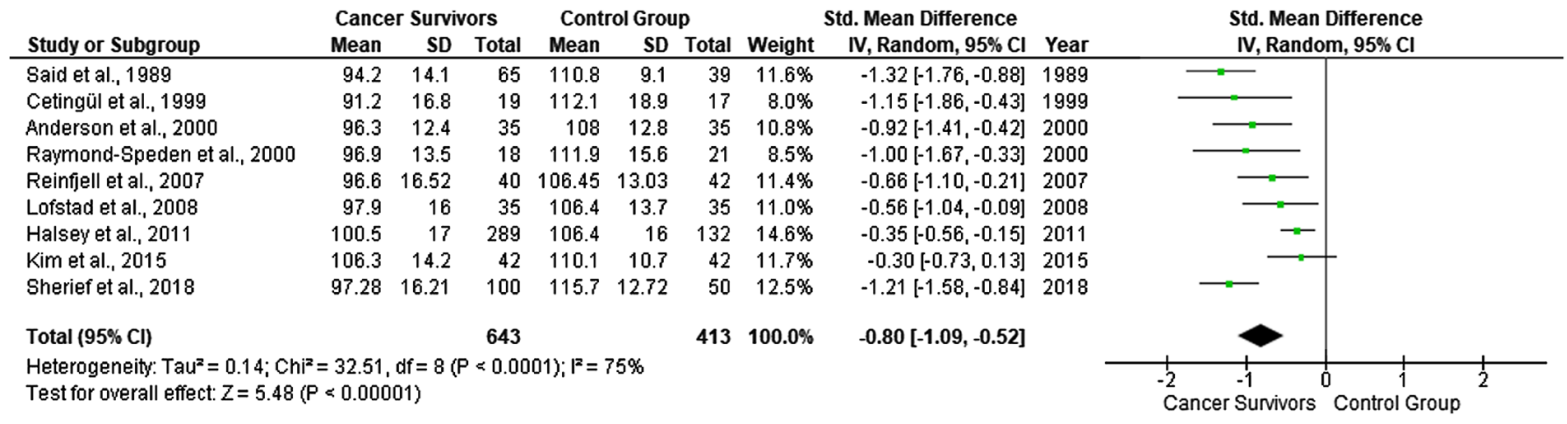

Figure 4. Forest plot presenting the meta-analysis based on SMDs for the effect of WISC performance IQ. The studies listed are as follows: Said et al (18), Cetingül et al (19), Raymond-Speden et al (20), Anderson et al (21), Reinfjell et al (22), Lofstad et al (23), Halsey et al (26), Kim et al (30) and Sherief et al (33). SMD, standardized mean difference; WISC, Wechsler Intelligence Scale for Children; IQ, intelligence quotient.

\section{Discussion}

The present meta-analysis demonstrated clinically significant differences in the cognitive functions between children and adolescent ALL survivors in remission and controls in the domain of intelligence i.e., significantly lower scores of total IQ, verbal IQ and performance IQ of CCS than healthy controls. The mean total IQ range was 85.2-107.2 in the CCS and 88.4-114.1 in the controls. The difference in the mean total IQ between controls and CCS ranged from -13.8 to 20.6.

Limitations of the present meta-analysis include the relatively small sample size, as well as the lack of baseline 
assessment of cognitive function prior to ALL treatment and longitudinal prospective follow-up. Yet, in the literature, the vast majority of studies addressing neurocognitive morbidity in children with cancer are case-control studies conducted after the cancer treatment had been completed.

ALL is primarily an early childhood disease with a peak in incidence between the ages of 1 and 4 years (34), a period during which robust brain development is highly susceptible to the effects of toxic agents. From a developmental perspective, as opposed to adults, any insult from CNS lesions or toxic agents (chemotherapy, radiation therapy) to the emerging neural networks of the pediatric brain is expected to have a significant impact that will be anything but static (35).

The treatment for ALL includes highly effective antileukemic chemotherapy and irradiation, both of which are associated with cognitive impairments and changes in CNS structure and function as indicated by imaging and cognitive studies (2).

Chemotherapy damages the DNA, either directly or through an increase in oxidative stress. Caron et al demonstrated that greater oxidated cerebrospinal fluid (CSF) phosphatidylcholine was linked to decreased executive function in children receiving chemotherapy for ALL (36). In addition, the CSF homocysteine levels of patients have been found to be inversely related to cognitive function before treatment and increased during treatment for ALL (37). Chemotherapy is also linked to the shortening of telomere length and, thus, cell aging, neuroinflammation via systemic cytokine release, and the reduction of brain vascularization and blood flow (38). The brains of children are more vulnerable to cancer treatment; toxicity can occur more easily due to its higher metabolic activity and lower stability of newly synthesized myelin (39). Supportive of the hypothesis that oxidative stress/neuroinflammation contribute to the chemotherapy-induced neurocognitive decline in pediatric ALL is the study by Cole et al (40). That study on 350 pediatric ALL survivors identified polymorphisms in 3 genes associated with an increased susceptibility to oxidative stress and/or neuroinflammation [endothelial nitric oxide synthase (NOS3), catechol-O-methyltransferase (COMT), hemochromatosis (HFE), glutathione S-transferase pi (GSTP1) and prostaglandin transporter (SLCO2A1)] as predictors of an inferior neurocognitive outcome. Chemotherapy is a potent neuro- and glio-toxin via excitotoxic and apoptotic mechanisms that may disrupt neurogenesis, myelination, neuronal network formation, neurogenesis of the hippocampus (which plays a critical role in memory formation) and cortical thinning of the developing brain (38). Chemotherapy is a major contributor to CNS toxicity, as it is associated with leukoencephalopathy, and decreased grey and white matter volumes in cortical and several subcortical brain regions, in the CCS of ALL, indicative of either cell loss and/or impaired development $(38,41)$. The aforementioned chemotherapy-induced CNS changes have been found to be associated with neurocognitive deficits in memory, processing speed, attention, intellect and academic achievements (38).

Chemotherapy-induced leukoencephalopathy is a known complication of methotrexate (the basic component of first-line treatment in pediatric ALL), as well as of fludarabine and cytarabine which are used in relapsed ALL. Leukoencephalopathy is mild and reversible in a number of cases, whereas in cases where methotrexate is combined with radiation therapy, leukoencephalopathy may be irreversible (42-47). However, intrathecal methotrexate with no radiation therapy can cause the same type of toxic leukoencephalopathy (48-51).

Neurocognitive toxicity in the late 1900s was attributed to the combined multiagent chemotherapy and radiation regimens. Nevertheless, CCS of ALL treated solely with polychemotherapy also demonstrate lower IQ scores (52).

Thus, the relative contributions of chemotherapy and radiation therapy to the neurocognitive toxicity are possibly moderated by several other risk factors, which have not yet been fully elucidated. Such risk factors are methotrexate and radiation dosage regimens and modes of administration, diluents, pre-existing folate deficiency, idiosyncratic predispositions $(42,53)$ and individual genetic factors that affect drug pharmacokinetics and pharmacodynamics (2). The risk of toxic effects seems to be influenced by age, with more severe intellectual outcomes demonstrated in patients treated for ALL before the age of 6 (52), as well as in ALL survivors approaching middle age (54).

Social implications of the cognitive and learning difficulties caused by pediatric cancer include school bullying and problems with social integration. The long periods of absence of CCS from school due to their ongoing clinical interventions is another component aggravating their social interactions. Another factor that must also be considered is that during the long process of overcoming the overall effects (physical, psychological, etc.) of pediatric cancer and then resuming a normal life, CCS may experience social isolation and lose motivation to overcome their difficulties. All activities evaluated in the reviewed studies (e.g., vocabulary and arithmetic abilities and information processing) are important for the individuals' academic achievements and professional careers $(8,11,55)$. Cognitive abilities and academic skills determine, to a great extent, the individual's occupation and employment, although professional occupation and overall quality of life are not always related to education. A previous study on survivors of CNS tumors reported higher unemployment rates than among healthy controls and survivors of other types of childhood cancers (56).

On the other hand, brain 'plasticity' early in life provides a 'window' of opportunity to minimize toxic effects by intervening as early as possible. For children experiencing the toxic effects of chemotherapy or radiotherapy, specialized early interventions are needed to minimize these consequences and achieve the best possible outcomes. The educational environment is one of the primary settings for implementing interventions for CCS of ALL. Investments in the development of specially designed and organized educational classes and programs are a priority, for children and adolescent CCS to overcome any learning, neurocognitive or psychosocial difficulties (11). The design of flexible and special education classes will allow educators to help CCS finish school, improve their academic outcomes and their overall quality of life. School re-entry programs to facilitate the adjustment of CCS at their return to school have been developed by several cancer centers. Direct educational services and interventions are considered as critical components of the holistic care of CCS to address their cognitive and social-emotional needs (35). Special educators must closely monitor the perfor- 
mance and behavior of CCS in order to early identify potential deficiencies in both their educational performance and their social life (12). Close neurocognitive monitoring along their treatment will help healthcare professionals involved in the care of CCS to take more informed decisions regarding their clinical, educational, and psychological interventions. Cognitive rehabilitation programs, such as the Attention Process Training (57) and Pay Attention! (58) have demonstrated some efficacy in addressing attention problems in leukemia (59). Computerized programs have also been developed to manage deficits in the working memory of children with attention deficit hyperactivity disorder (60). In addition, pharmacotherapy can be used for fatigue or mood-associated problems, whereas medications used in adult cognitive dysfunction are under investigation (61). Furthermore, social support with networking and organized group activities, can alleviate feelings of social isolation. The first interactive website LEAP3 AHEAD that provides comprehensive, age and audience specific information about late effects in CCS of ALL, was recently developed by Klonoff-Cohen et al (62). The 'Late Effects Awareness for the Physicians, Patients, specifically, survivors with acute lymphocytic leukemia, and the Public: Advancing Health and Eliminating All Disparities' (LEAP3 AHEAD) is designed to educate the public, CCS (of all ages) and the professionals involved in their care about cancer's late effects and to provide suggestions for successful school and social reintegration (62).

As the survival rates of children and adolescents with ALL and cancer in general are steadily increasing, the regular, lifelong follow-up for neurocognitive late effects is imperative in order to improve their education and employment prospects and overall, their quality of life. State authorities and private organizations across the globe must raise awareness about the cognitive and educational consequences of pediatric cancer. Over the next years, in-depth knowledge of the genomic landscape of ALL will provide the basis to harness precision medicine. Major challenges will be to identify prognostic biomarkers, introduce molecularly-targeted dosage regimens, to refine complex, toxic therapies and incorporate treatments that counteract or prevent cognitive sequelae.

\section{Acknowledgements}

Not applicable.

\section{Funding}

No funding was received.

\section{Availability of data and materials}

All data analyzed during the present study are included in this published article.

\section{Authors' contributions}

KM was involved in the conceptualization and methodology of the study, and in the writing and preparation of the original draft, as well as in the reviewing and editing of the manuscript. VE was involved in the study methodology, as well as in data analysis and in the writing and preparation of the original draft, as well as in the reviewing and editing of the manuscript. KK was involved in the methodology of the study, and in the writing and preparation of the original draft, as well as in the reviewing and editing of the manuscript. KT, CKG, DAS, GC and $\mathrm{AK}$ were involved in data analysis and in the writing, reviewing and editing of the manuscript. FB was involved in the conceptualization, supervision and methodology of the study, as well as in the writing and preparation of the original draft, and in the reviewing and editing of the manuscript. $\mathrm{KM}, \mathrm{VE}$ and FB confirm the authenticity of all raw data. All authors read and approved the final manuscript.

\section{Ethics approval and consent to participate}

Not applicable.

\section{Patient consent for publication}

Not applicable.

\section{Competing interests}

DAS is the Editor-in-Chief for the journal, but had no personal involvement in the reviewing process, or any influence in terms of adjudicating on the final decision, for this article. The other authors declare that they have no competing interests. The authors are responsible for the choice and presentation of views contained in this article and for opinions expressed therein, which are not necessarily those of UNESCO and do not commit the Organization.

\section{References}

1. Howlader N, Noone AM, Krapcho M, Garshell J, Neyman N, Altekruse SF, Kosary CL, Yu M, Ruhl J, Tatalovich Z, et al (eds): SEER Cancer Statistics Review, 1975-2010. National Cancer Institute, Bethesda, MD, 2013.

2. Hunger SP and Mullighan CG: Acute lymphoblastic leukemia in children. N Engl J Med 373: 1541-1552, 2015.

3. Van Dongen-Melman JE: Developing psychosocial aftercare for children surviving cancer and their families. Acta Oncol 39: 23-31, 2000.

4. Mohrmann C, Henry J, Hauff M and Hayashi RJ: Neurocognitive outcomes and school performance in solid tumor cancer survivors lacking therapy to the central nervous system. J Pers Med 5: 83-90, 2015.

5. Askins MA and Moore BD III: Preventing neurocognitive late effects in childhood cancer survivors. J Child Neurol 23 . 1160-1171, 2008

6. Bhatia S and Constine LS: Late morbidity after successful treatment of children with cancer. Cancer J 15: 174-180, 2009.

7. de Ruiter MA, Schouten-Van Meeteren AYN, van Mourik R, Janssen TWP, Greidanus JEM, Oosterlaan J and Grootenhuis MA: Neurofeedback to improve neurocognitive functioning of children treated for a brain tumor: Design of a randomized controlled double-blind trial. BMC Cancer 12: 581-589, 2012.

8. De Houwer J, Barnes-Holmes D and Moors A: What is learning? On the nature and merits of a functional definition of learning. Psychon Bull Rev 20: 631-642, 2013.

9. Celiköz N, Erișen Y and Sahin M: Cognitive learning theories. In: Learning and Teaching: Theories, Approaches and Models. Akdemir AS, Kaya Z and Akdemir OA (eds). 1st English Edition. Cözüm Publishing, Ankara, 2016.

10. Wenger BL, Kaye HS and La Plante MP: Disabilities Among Children. In: Disability Statistics Abstract No. 15. U.S Department of Education, National Institute on Disability and Rehabilitation Research, Washington, DC, 1995. 
11. Institute of Medicine (US) and National Research Council (US) National Cancer Policy Board, Hewitt M, Weiner SL and Simone JV (eds): Childhood Cancer Survivorship: Improving Care and Quality of Life. National Academies Press, Washington, DC, 2003.

12. Bisen-Hersh EB, Hineline PN and Walker EA: Disruption of learning processes by chemotherapeutic agents in childhood survivors of acute lymphoblastic leukemia and preclinical models. J Cancer 2: 292-301, 2011

13. Haupt R, Fears TR, Robison LL, Mills JL, Nicholson HS, Zeltzer LK, Meadows AT and Byrne J: Educational attainment in long-term survivors of childhood acute lymphoblastic leukemia. JAMA 272: 1427-1432, 1994

14. Vardy J, Wefel JS, Ahles T, Tannock IF and Schagen SB: Cancer and cancer-therapy related cognitive dysfunction: An international perspective from the Venice cognitive workshop. Ann Oncol 19: 623-629, 2008

15. Brown RT, Sawyer MB, Antoniou G, Toogood I, Rice M, Thompson N and Madan-Swain A: A 3-year follow-up of the intellectual and academic functioning of children receiving central nervous system prophylactic chemotherapy for leukemia. J Dev Behav Pediatr 17: 392-398, 1996.

16. Zhou C, Zhuang Y, Lin X, Michelson AD and Zhang A: Changes in neurocognitive function and central nervous system structure in childhood acute lymphoblastic leukaemia survivors after treatment: A meta-analysis. Br J Haematol 188: 945-961, 2020.

17. Liberati A, Altman DG, Tetzlaff J, Mulrow C, Gøtzsche PC, Ioannidis JP, Clarke M, Devereaux PJ, Kleijnen J and Moher D: The PRISMA statement for reporting systematic reviews and meta-analyses of studies that evaluate health care interventions: Explanation and elaboration. PLoS Med 6: e1000100, 2009.

18. Said JA, Waters BGH, Cousens $\mathrm{P}$ and Stevens MM: Neuropsychological sequelae of central nervous system prophylaxis in survivors of childhood acute lymphoblastic leukemia. J Consult Clin Psychol 57: 251-256, 1989.

19. Cetingül N, Aydinok Y, Kantar M, Oniz H, Kavakli K, Yalman O, Erermiş S, Celebisoy N, Akyürekli O, Oztop S, et al: Neuropsychologic sequelae in the long-term survivors of childhood acute lymphoblastic leukemia. Pediatr Hematol Oncol 16: 213-220, 1999.

20. Raymond-Speden E, Tripp G, Lawrence B and Holdaway D: Intellectual, neuropsychological, and academic functioning in long-term survivors of leukemia. J Pediatr Psychol 25: 59-68, 2000 .

21. Anderson VA, Godber T, Smibert E, Weiskop S and Ekert H: Cognitive and academic outcome following cranial irradiation and chemotherapy in children: A longitudinal study. Br J Cancer 82: 255-262, 2000.

22. Reinfjell T, Lofstad GE, Veenstra M, Vikan A and Diseth TH Health-related quality of life and intellectual functioning in children in remission from acute lymphoblastic leukaemia. Acta Paediatr 96: 1280-1285, 2007.

23. Lofstad GE, Reinfjell T, Hestad K and Diseth TH: Cognitive outcome in children and adolescents treated for acute lymphoblastic leukaemia with chemotherapy only. Acta Paediatr 98 180-186, 2009.

24. Carey ME, Haut MW, Reminger SL, Hutter JJ, Theilmann R and Kaemingk KL: Reduced frontal white matter volume in long-term childhood leukemia survivors: A voxel-based morphometry study. AJNR Am J Neuroradiol 29: 792-797, 2008.

25. Aukema EJ, Caan MWA, Oudhuis N, Majoie CBLM, Vos FM, Reneman L, Last BF, Grootenhuis MA and Schouten-van Meeteren AYN: White matter fractional anisotropy correlates with speed of processing and motor speed in young childhood cancer survivors. Int J Radiat Oncol Biol Phys 74: 837-843, 2009.

26. Halsey C, Buck G, Richards S, Vargha-Khadem F, Hill F and Gibson B: The impact of therapy for childhood acute lymphoblastic leukaemia on intelligence quotients; results of the risk-stratified randomized central nervous system treatment trial MRC UKALL XI. J Hematol Oncol 4: 42, 2011.

27. Zou P, Li Y, Conklin HM, Mulhern RK, Butler RW and Ogg RJ: Evidence of change in brain activity among childhood cancer survivors participating in a cognitive remediation program. Arch Clin Neuropsychol 27: 915-929, 2012.

28. Kesler SR, Gugel M, Pritchard-Berman M, Lee C, Kutner E, Hosseini SM, Dahl G and Lacayo N: Altered resting state functional connectivity in young survivors of acute lymphoblastic leukemia. Pediatr Blood Cancer 61: 1295-1299, 2014.
29. Reddick WE, Taghipour DJ, Glass JO, Ashford J, Xiong X, Wu S, Bonner M, Khan RB and Conklin HM: Prognostic factors that increase the risk for reduced white matter volumes and deficits in attention and learning for survivors of childhood cancers. Pediatr Blood Cancer 61: 1074-1079, 2014.

30. Kim SJ, Park MH, Lee JW, Chung NG, Cho B, Lee IG and Chung SY: Neurocognitive outcome in survivors of childhood acute lymphoblastic leukemia: Experience at a tertiary care hospital in Korea. J Korean Med Sci 30: 463-469, 2015.

31. Van Der Plas E, Erdman L, Nieman BJ, Weksberg R, Butcher DT, O'connor DL, Aufreiter S, Hitzler J, Guger SL, Schachar RJ, et al: Characterizing neurocognitive late effects in childhood leukemia survivors using a combination of neuropsychological and cognitive neuroscience measures. Child Neuropsychol 24: 999-1014, 2018.

32. Darling S, De Luca CR, Anderson V, McCarthy M, Hearps S and Seal M: Brain morphology and information processing at the completion of chemotherapy-only treatment for pediatric acute lymphoblastic leukemia. Dev Neurorehabil 22: 293-302, 2019.

33. Sherief LM, Sanad R, ElHaddad A, Shebl A, Abdelkhalek ER Elsafy ER, Hassan TH, Raafat N, Kamal NM and Attia EI: A cross-sectional study of two chemotherapy protocols on long term neurocognitive functions in Egyptian children surviving acute lymphoblastic leukemia. Curr Pediatr Rev 14: 253-260, 2018.

34. Malard F and Mohty M: Acute lymphoblastic leukaemia. Lancet 395: 1146-1162, 2020

35. Rey-Casserly C and Meadows ME: Developmental perspectives on optimizing educational and vocational outcomes in child and adult survivors of cancer. Dev Disabil Res Rev 14: 243-250, 2008

36. Caron JE, Krull KR, Hockenberry M, Jain N, Kaemingk K and Moore IM: Oxidative stress and executive function in children receiving chemotherapy for acute lymphoblastic leukemia. Pediatr Blood Cancer 53: 551-556, 2009.

37. Cole PD, Beckwith KA, Vijayanathan V, Roychowdhury S, Smith AK and Kamen BA: Folate homeostasis in cerebrospinal fluid during therapy for acute lymphoblastic leukemia. Pediatr Neurol 40: 34-41, 2009.

38. Ikonomidou C: Chemotherapy and the pediatric brain. Mol Cell Pediatr 5: 8, 2018.

39. Pääkkö E, Harila-Saari A, Vanionpää L, Himanen S, Pyhtinen J and Lanning M: White matter changes on MRI during treatment in children with acute lymphoblastic leukemia: Correlation with neuropsychological findings. Med Pediatr Oncol 35: 456-461, 2000.

40. Cole PD, Finkelstein Y, Stevenson KE, Blonquist TM, Vijayanathan V, Silverman LB, Neuberg DS, Sallan SE, Robaey P and Waber DP: Polymorphisms in genes related to oxidative stress are associated with inferior cognitive function after therapy for childhood acute lymphoblastic leukemia. J Clin Oncol 33: 2205-2211, 2015

41. van der Plas E, Schachar RJ, Hitzler J, Crosbie J, Guger SL, Spiegler BJ, Ito S and Nieman BJ: Brain structure, working memory and response inhibition in childhood leukemia survivors. Brain Behav 7: e00621, 2016.

42. Cruz-Sanchez FF, Artigas J, Cervos-Navarro J, Rossi ML and Ferszt R: Brain lesions following combined treatment with methotrexate and craniospinal irradiation. J Neurooncol 10: 165-171, 1991.

43. Antunes NL, Souweidane MM, Lis E, Rosenblum MK and Steinherz PG: Methotrexate leukoencephalopathy presenting as Klüver-Bucy syndrome and uncinate seizures. Pediatr Neurol 26 : 305-308, 2002.

44. DeAngelis LM, Seiferheld W, Schold SC, Fisher B and Schultz CJ; Radiation Therapy Oncology Group Study 93-10: Combination chemotherapy and radiotherapy for primary central nervous system lymphoma: Radiation Therapy Oncology Group Study 93-10. J Clin Oncol 20: 4643-4648, 2002.

45. Lai R, Abrey LE, Rosenblum MK and DeAngelis LM Treatment-induced leukoencephalopathy in primary CNS lymphoma: A clinical and autopsy study. Neurology 62: 451-456, 2004.

46. Rubinstein LJ, Herman MM, Long TF and Wilbur JR: Disseminated necrotizing leukoencephalopathy: A complication of treated central nervous system leukemia and lymphoma. Cancer 35: 291-305, 1975

47. Stone JA, Castillo M and Mukherji SK: Leukoencephalopathy complicating an Ommaya reservoir and chemotherapy. Neuroradiology 41: 134-136, 1999.

48. Abelson HT: Methotrexate and central nervous system toxicity. Cancer Treat Rep 62: 1999-2001, 1978. 
49. Allen JC,Rosen G,Mehta BMandHorten B:Leukoencephalopathy following high-dose iv methotrexate chemotherapy with leucovorin rescue. Cancer Treat Rep 64: 1261-1273, 1980.

50. Omuro AM, DeAngelis LM, Yahalom J, Abrey LE, DeAngelis LM, Yahalom $J$ and Abrey LE: Chemoradiotherapy for primary CNS lymphoma: An intent-to-treat analysis with complete follow-up. Neurology 64: 69-74, 2005.

51. Lövblad K, Kelkar P, Ozdoba C, Ramelli G, Remonda L and Schroth G: Pure methotrexate encephalopathy presenting with seizures: CT and MRI features. Pediatr Radiol 28: 86-91, 1998.

52. Sleurs C, Lemiere J, Vercruysse T, Nolf N, Van Calster B, Deprez S, Renard M, Vandecruys E, Benoit Y and Uyttebroeck A: Intellectual development of childhood ALL patients: A multicenter longitudinal study. Psychooncology 26: 508-514, 2017.

53. Perry A and Schmidt RE: Cancer therapy-associated CNS neuropathology: An update and review of the literature. Acta Neuropathol 111: 197-212, 2006.

54. Krull KR, Brinkman TM, Li C, Armstrong GT, Ness KK, Srivastava DK, Gurney JG, Kimberg C, Krasin MJ, Pui CH, et al: Neurocognitive outcomes decades after treatment for childhood acute lymphoblastic leukemia: A report from the St Jude lifetime cohort study. J Clin Oncol 31: 4407-4415, 2013.

55. Barrera M, Shaw AK, Speechley KN, Maunsell E and Pogany L: Educational and social late effects of childhood cancer and related clinical, personal, and familial characteristics. Cancer 104 1751-1760, 2005.
56. Dumas A, Berger C, Auquier P, Michel G, Fresneau B, Allodji RS, Haddy N, Rubino C, Vassal G, Valteau-Couanet D, et al: Educational and occupational outcomes of childhood cancer survivors 30 years after diagnosis: A French cohort study. Br J Cancer 114: 1060-1068, 2016.

57. Sohlberg M and Mateer C: Attention Process Training (APT), Association for Neuropsychological Research and Development, Washington, DC, 1987.

58. Thomson J and Kerns K: Pay Attention! A children's attention process training program. 2nd edition. Lash \& Associates Publishing, Wake Forest, NC, 2005.

59. Penkman L: Remediation of attention deficits in children: A focus on childhood cancer, traumatic brain injury and attention deficit disorder. Pediatr Rehabil 7: 111-123, 2004.

60. Klingberg T, Fernell E, Olesen PJ, Johnson M, Gustafsson P, Dahlström K, Gillberg CG, Forssberg $\mathrm{H}$ and Westerberg $\mathrm{H}$ : Computerized training of working memory in children with ADHD - a randomized, controlled trial. J Am Acad Child Adolesc Psychiatry 44: 177-186, 2005.

61. Shaw EG, Rosdhal R, D'Agostino RB Jr, Lovato J, Naughton MJ, Robbins ME and Rapp SR: Phase II study of donepezil in irradiated brain tumor patients: Effect on cognitive function, mood, and quality of life. J Clin Oncol 24: 1415-1420, 2006.

62. Klonoff-Cohen H, Navarro A and Klonoff EA: Late effects awareness website for pediatric survivors of acute lymphocytic leukemia. PLoS One 13: e0193141, 2018. 